\title{
The Association between Body Mass Index (BMI), Leg Power, Speed, and Cardiorespiratory Fitness (CRF) among Adolescents
}

\author{
Dzihan Khilmi Ayu Firdausi \\ Department of Physical Education, Health and Recreation \\ Higher School of Teacher Training and Education of \\ Muhammadiyah Bangka Belitung \\ Pangkalpinang, Indonesia \\ dzihanayu@gmail.com
}

\author{
Muhammad Eka Mardyansyah Simbolon \\ Department of Physical Education, Health and Recreation \\ Higher School of Teacher Training and Education of \\ Muhammadiyah Bangka Belitung \\ Pangkalpinang, Indonesia \\ simbolon@stkipmbb.ac.id
}

\begin{abstract}
- the aim of this research is to examine the relationship between the Body Mass Index, leg power, speed, and cardiorespiratory fitness among adolescents living in Bangka Belitung Islands. 105 adolescents with an average age of 18 years were randomly selected from senior high school graduates. These adolescents where made to undertake a physical examination at the Physical Education Health and Recreation Department of the Teacher Training and Education of Muhammadiyah Bangka Belitung. The measured variables were the height, body mass, vertical jump (leg power), speed (60 meters), and 1000-1200 meters run/walk (cardiorespiratory fitness). Results obtained showed BMI to be significantly correlated with a leg power value of $t=4.97$, and $p<0.05$, a speed value of $t=4.04$, and $p<0.05$. The results also proved that the CRF was not significantly correlated with BMI which had a $t$ value of $0.30, p>0.05$; leg power value of $t=0.71, p>0.05$; and a speed of $t=1.12$ in which its $p$ is greater than 0.05 . Adolescent's leg power was average, but their speed was fair, and the CRF was poor. From the results obtained, the various variables associated need to be given attention and enhanced especially speed and CRF in order to develop a fit adolescent.
\end{abstract}

Keyword-Adolescents, BMI, CRF, Power, Speed

\section{INTRODUCTION}

The use of automation and other technologies have contributed greatly to the reduction of physical activities at home, school, and work place.[1] Analysis has it that this might lead to overweight and obesity among adolescents if not properly checked. Childhood and adolescence are crucial periods of life, since tremendous physiological and psychological changes take place at these stages of development.[2] This common health decline between toddlers and adolescents, has become a great concern for both Canada and England. Both countries have taken it upon themselves to independently document secular declines in health-related fitness among children and youths.[3] Obesity, overweight, and poor physical fitness of children could lead to many diseases. It could also present a series of health problem on these set of people in the nearest future.[4] The presence of Obesity among toddlers and adolescents currently is increasing at an alarming rate. Obesity is associated with the presence of excessive body fat that increases the risk of health problems. Children with high body fat levels have low cardiorespiratory fitness.[5] The percentage of fat and fat mass has strong strength against $\mathrm{VO}_{2} \max$ in boys.[1] Other studies, found no significant difference in cardiorespiratory fitness between men and women.[6]

An increase in the PA levels (physical activity levels), in adolescents has been associated with improved cardiorespiratory status which helps in reducing the risk associated with contacting non-communicable diseases (NCDs).[7] Physical activities such as walking, jumping and running is said to have a huge effect to the prevention of obesity, NCDs, and weight related diseases. Adolescence is an important period for the prevention of NCDs as physical inactivity and poor physical fitness at early adolescence are associated with the development of NCDs during adulthood.[8] It is common to see children and adolescents with a reduced insulin resistance, elevated triglyceride concentrations, central obesity, low cardiorespiratory fitness (CRF), physical inactivity and low high density lipoprotein (HDL) concentrations.[9] Educational institutions are considered as one of the outstanding places that provide students with the opportunity to exercise daily through PA, by learning the importance of regular PA to health, and by building the skills that support active lifestyles.[10]

The body mass index (BMI) is the universally accepted tool used for screening the weight status of toddlers and adolescents.[11] Childhood and adolescent obesity is associated with several adverse health conditions, such as higher risks of cardiovascular disease, type 2 diabetes and hypertension.[12] For example, a recent estimate found the metabolic syndrome to be $39 \%$ in children found to be overweight and as high as $50 \%$ in obese children and adolescents between the ages of 4-20 years.[13] High levels of cardiorespiratory fitness have consistently been found to negatively correlate with markers of obesity in young people including body mass index (BMI).[12] Data obtained has it that most obese children will eventually become obese adults, thus there is an urgent need to better understand and respond to this international epidemic.[13] This study aims to provide an empirical information of the condition of BMI, speed, leg power, and CRF among adolescents in Bangka Belitung Islands in 2017. This study also shows the link between BMI and CRF, with respect to leg power and speed of adolescent. 


\section{METHODS}

\section{A. Participants}

The participants used in carrying out this study are adolescent high school students between the ages of 17-21 years. The participants also took a physical test at the Physical Education, Health and Recreation department of STKIP Muhammadiyah Bangka Belitung in 2017. 105 adolescents participated in the anthropometry and performance test. The participants were made up of 90 boys and 15 girls. The research was approved by the Institute of Research and Community Service of the Higher Teacher Training and Education School loated in Muhammadiyah Bangka Belitung. There was also a written approval from the parents and guardians of the students used in carrying out this research.

\section{B. Body Mass Index}

Body mass index is calculated by dividing the body mass $(\mathrm{kg})$ by the squared body height $\left(\mathrm{m}^{2}\right)$. The participants are grouped into the 'normal' category $\left(<24.9 \mathrm{~kg} / \mathrm{m}^{2}\right.$, including underweight), 'overweight' category (25.0-29.9 kg/m²), and 'obesity' category (> $30.0 \mathrm{~kg} / \mathrm{m}^{2}$ ).[14] Participants' height and mass were measured by senior students trained in the field of anthropometry. . Participants were asked to step in barefooted and lightly dressed during the anthropometry test. The height and mass of the sample body were measured in kilogram $(\mathrm{kg})$ using a scale, while the height was measured in meter with a meter rule calibrated in centimeter.

\section{Leg Power and Speed}

Vertical jumps was used to measure participants' leg power. Each participant was allowed to make a vertical jump three times. They were all advised to jump as high as possible. The results of the jump was measured and recorded on a centimeter scale $(\mathrm{cm})$. The highest jump distance was hence taken to predict the leg power.[15] The speed is measured using a 60 meter sprint performance test.[15] Each participant is given two opportunity to dash 60 meters. The fastest time taken to complete a 60 -meter dash between the two given opportunity was recorded and taken.

\section{Cardiorespiratory Fitness}

1000 and 1200 meters Running / walking tests was used to measure the respiratory durability of the participants. The performance of field test run / walk medium-haul road was 1200 meters for men and 1000 meters for the women.[15] All participants were instructed to complete the test as soon as possible. However, they were allowed to walk if they couldn't run. The time taken by the participants is recorded in minutes and seconds using a calibrated stopwatch.

\section{E. Data analysis}

Descriptive statistics was used to provide an overview of the participant characteristics and research variables. Pearson's correlation was used to examine the relationship between body mass index and the physical fitness including the respiratory durability of participants. The significance test was measured using t test while the significance level used for all analyzes is 0.05 . All statistical analysis on this research data is using Microsoft Excel 2013 for windows 7 operating system.

\section{RESULTS AND DISCUSSION}

The characteristics of each participant can be seen in table 1 . Overall boys have more body weight and height than girls. Nevertheless, both boys $\left(21.53 \mathrm{~kg} / \mathrm{m}^{2}\right)$ and girls $(22.06$ $\mathrm{kg} / \mathrm{m}^{2}$ ) have a 'normal' body mass index.[14] The CRF performance of girls (6.91) was better than boys (6.44), but overall the CRF of both sexes is 'poor.' The Girls leg power which had a value of 39.27, was tagged a 'good' calcification compared to boys leg power which had a value of 55.84 and tagged an 'Average' calcification. However, overall adolescent leg power (53.47) was classified as 'average.' The speed values of both boys (10.47) and girls (12.18) was classified 'fair.' Boys performed better than girls in speed, muscular strength, and CRF, while girls performed better than boys in balance and flexibility.[16]

TABLE I. The PARTICIPANT CHARACTERISTICS

\begin{tabular}{lrccc}
\hline & \multicolumn{1}{c}{ All } & \multicolumn{1}{c}{ Boys } & \multicolumn{1}{c}{ Girls } \\
\hline$n$ & \multicolumn{2}{c}{105} & 90 & \multicolumn{1}{c}{15} \\
Age (years) & $18.48 \pm 1.57$ & $18.64 \pm 1.62$ & $17.37 \pm 0.74$ \\
Body mass $(\mathrm{kg})$ & $58.33 \pm 11.21$ & $59.12 \pm 11.55$ & $53.60 \pm 8.10$ \\
Body height $(\mathrm{m})$ & $1.64 \pm 0.07$ & $1.65 \pm 0.06$ & $1.56 \pm 0.04$ \\
BMI $\left(\mathrm{kg} / \mathrm{m}^{2}\right)$ & $21.61 \pm 3.60$ & $21.53 \pm 3.59$ & $22.06 \pm 3.78$ \\
Leg Power & $53.47 \pm 11.51$ & $55.84 \pm 10.27$ & $39.27 \pm 7.90$ \\
Speed & $10.71 \pm 1.20$ & $10.47 \pm 1.06$ & $12.18 \pm 0.99$ \\
CRF & $6.51 \pm 1.04$ & $6.44 \pm 1.05$ & $6.91 \pm 0.90$ \\
\hline
\end{tabular}

Notes. Value are mean $\pm S D$; Speed (60 meter dash); Leg Power (vertical jump); CRF = Cardiorespiratory Fitness (1000 and 1200 run/walk).

Table 2 shows the relationship between each variable. Body weight has a strong positive correlation with BMI ( $r$ ) having a value of 0.891 . Body height correlated relatively small positive with BMI $(r=0.036)$. The leg power was moderately and negatively correlated with BMI $(r=-0.439)$. The speed was moderately and positively correlated with BMI $(r=0.372)$. The cardiorespiratory Fitness was a relatively small positive correlation with body mass index $(r=0.027)$.

TABLE II. THE CORRELATIONS SCORE BETWEEN VARIABLES

\begin{tabular}{lccccc}
\hline & $\begin{array}{c}\text { Body } \\
\text { weight }\end{array}$ & $\begin{array}{c}\text { Body } \\
\text { Height }\end{array}$ & Leg Power & Speed & CRF \\
\hline BMI & 0.891 & 0.036 & $\mathbf{- 0 . 4 3 9}$ & $\mathbf{0 . 3 7 2}$ & $\mathbf{0 . 0 2 7}$ \\
Body Weight & - & 0.476 & -0.457 & 0.409 & -0.018 \\
Body Height & & - & -0.137 & 0.160 & -0.086 \\
Leg Power & & & - & -0.383 & $\mathbf{- 0 . 0 7 3}$ \\
Speed & & & & - & $\mathbf{0 . 1 0 7}$ \\
CRF & & & & & - \\
\hline
\end{tabular}

Body height was positively moderate correlation with body weight $(r=0.476)$. The CRF was correlated negatively small with body weight, body height, and leg power $(r=-$ 0.018, $r=-0.086, r=-0.073)$. However, the CRF was correlated positively with speed $(r=0.107)$.

TABLE III. The CORRELATION SIGNIFICANCE TEST SCORE

\begin{tabular}{lcc}
\hline & BMI & CRF \\
\hline Leg Power & 4.97 & 0.71 \\
Speed & 4.04 & 1.12 \\
CRF & 0.30 & - \\
\hline$n=105, t_{\text {table }}=1.66$ & &
\end{tabular}

Based on the results of the correlation significance test presented in table 3. It can be seen that BMI has a significant correlation with leg power $(\mathrm{t}=4.97, \mathrm{p}<0.05)$, and speed $(\mathrm{t}=$ 
4.04, $\mathrm{p}<0.05)$. CRF was not significantly correlated with BMI $(t=0.30, p>0.05)$, leg power $(t=0.71, p>0.05)$, and speed $(t=1.12 p>0.05)$. Liao et al. stated that the strength and power of the lower body, has a high correlation with adolescents' BMI especially with those living in Taiwan.[12] In Benson et.al. study, both strength and cardiorespiratory fitness where found to maintain their protective effects after adjusting the other physical fitness parameters. This emphasized that these two components of the fitness are independent of each other and not surrogate measures of each other.[13] Body mass index and cardiorespiratory fitness both have a significant correlation with strength and endurance of the arm muscle.[17] Muscle fitness and CRF were significantly and negatively correlated with the risk of cardio metabolic.[9] There are no significant correlation between the Body mass index and the cardiorespiratory fitness. Same is applicable to, body mass index and cardiorespiratory fitness with abdominal muscle strength and endurance.[17]

It is, therefore, important to maintain a normal BMI in toddlers during their primary school years in order to achieve and maintain better physical fitness.[18] Adolescents that undergo physical activities more often, tend to demonstrate higher BMI, proportional body composition and a better level of cardiorespiratory fitness compared to those that do not.[19] Based on the results of this study it was found that BMI and CRF were only correlated with arm muscle strength and endurance. The other research findings suggest that body fat is strongly related to cardiovascular risk, but when the outcome is calculated without the central obesity indicator, CRF becomes more related to metabolic risk.[20]

\section{CONCLUSION}

In conclusion, the Adolescent's leg power was found to be average, with a fair speed, and a poor CRF. These conditions needs to be given adequate attention and properly enhanced especially with regards to speed and CRF in order to develop a fit and healthy adolescent.

\section{ACKNOWLEDGMENT}

The authors wish to thank the head and coordinator of Higher School of Teacher Training and Education of Muhammadiyah Bangka Belitung. We also wish to express our gratitude to all those who in one way or another assisted us in collecting data, as well as all those involved in the project.

\section{REFERENCES}

[1] B. Sadhan, S. Koley, and J. S. Sandhu, "Relationship Between Cardiorespiratory Fitness, Body Composition and Blood Pressure in Punjabi Collegiate Population," J. Hum. Ecol., vol. 22, no. 3, pp. 215219, 2007.

[2] F. B. Ortega, J. R. Ruiz, M. J. Castillo, and M. Sjöström, "Physical fitness in childhood and adolescence: A powerful marker of health," Int.
J. Obes., vol. 32, no. 1, pp. 1-11, 2008.

[3] C. Voss et al., "A cross-cultural comparison of body composition, physical fitness and physical activity between regional samples of Canadian and English children and adolescents.," Can. J. Public Health, vol. 105, no. 4, pp. e245-50, 2014.

[4] G. Starc and J. Strel, "Influence of the quality implementation of a physical education curriculum on the physical development and physical fitness of children," BMC Public Health, vol. 12, no. 1, p. 61, 2012

[5] L. P. Hunt, J. P. H. Shield, A. R. Cooper, A. R. Ness, and D. A. Lawlor, "Blood pressure in children in relation to relative body fat composition and cardio-respiratory fitness," Int. J. Pediatr. Obes., vol. 6, no. 3-4, pp. 275-284, 2011

[6] R. Ramsbottom, J. Currie, and M. Gilder, "Relationships between components of physical activity, cardiorespiratory fitness, cardiac autonomic health, and brain-derived neurotrophic factor," J. Sports Sci., vol. 28, no. 8, pp. 843-849, 2010.

[7] O. S. Olawale, M. Mwila, Y. M. E. Marie, and T. A. Lamina, "Relationship between Cardiorespiratory Fitness and Anthropometric Variables among School-going Adolescents in Nigeria," Anthropol., vol. 29, no. 1, pp. 65-72, 2017.

[8] S. Andrade et al., "A school-based intervention improves physical fitness in Ecuadorian adolescents: A cluster-randomized controlled trial," Int. J. Behav. Nutr. Phys. Act., vol. 11, no. 1, pp. 1-17, 2014.

[9] D. S. Buchan et al., "Relationships between Cardiorespiratory and Muscular Fitness with Cardiometabolic Risk in Adolescents," Res. Sport. Med., vol. 23, no. 3, pp. 227-239, 2015.

[10] Aboshkair, "Factors Affecting Levels of Health-Related Physical Fitness in Secondary School Students in Selangor, Malaysia," J. Basic Appl. Sci., vol. 8, pp. 202-216, 2012.

[11] Y. C. Huang and R. M. Malina, "Body mass index and individual physical fitness tests in Taiwanese youth aged 918 years," Int. J. Pediatr. Obes., vol. 5, no. 5, pp. 404-411, 2010.

[12] Y. Liao et al., "Associations between health-related physical fitness and obesity in Taiwanese youth," J. Sports Sci., vol. 31, no. 16, pp. 1797 1804, 2013.

[13] A. C. Benson, M. E. Torode, and M. A. Fiatarone Singh, "Muscular strength and cardiorespiratory fitness is associated with higher insulin sensitivity in children and adolescents," Int. J. Pediatr. Obes., vol. 1, no. 4, pp. 222-231, 2006.

[14] W. W. K. Hoeger and S. A. Hoeger, Principles and Labs for Physical Fitness. United States of America: Thomson Wadsworth, 2008.

[15] Widiastuti, Tes dan Pengukuran Olahraga. Jakarta: Bumi Timur Jaya, 2011.

[16] P. De Miguel-Etayo et al., "Physical fitness reference standards in European children: The IDEFICS study," Int. J. Obes., vol. 38, pp. S57S66, 2014.

[17] M. E. M. Simbolon and D. K. A. Firdausi, "Asosiasi antara Indeks Massa Tubuh, Kebugaran Tubuh Bagian Atas dan Daya Tahan Respirasi di Kalangan Remaja," Phys. Educ. Heal. Recreat., vol. 2, no. 2, pp. 118-123, 2018 .

[18] H. Chen, L. Housner, and Y. Gao, "The Influence of Weight Change on Physical Fitness from Childhood to Adolescence," Meas. Phys. Educ. Exerc. Sci., vol. 21, no. 3, pp. 113-120, 2017.

[19] M. D. Ahmed et al., "The self-esteem, goal orientation, and healthrelated physical fitness of active and inactive adolescent students," Cogent Psychol., vol. 4, no. 1, pp. 1-14, 2017.

[20] D. R. Silva et al., "Cardiorespiratory fitness effect may be underestimated in 'fat but fit' hypothesis studies," Ann. Hum. Biol., vol. 44, no. 3, pp. 237-242, 2017. 